\title{
COMUNICAÇÃO
}

\section{EFICÁCIA DA SANIFICAÇÃo NO PROCESSAMENTO MÍNIMO DE LARANJA 'PÊRA'}

\author{
Sanitization efficacy in minimal processing of 'Pera' orange
}

\author{
Maria Cecília de Arruda ${ }^{1}$, Angelo Pedro Jacomino², Raquel Capistrano Moreira ${ }^{3}$, Cláudio Rosa Gallo ${ }^{4}$
}

\begin{abstract}
RESUMO
A sanificação é uma das operações mais importantes em processamento mínimo. Objetivou-se, neste trabalho, determinar em qual etapa do processamento mínimo de laranja, a sanificação é mais eficaz. Os frutos foram selecionados quanto à coloração da casca e tamanho e resfriados a $6^{\circ} \mathrm{C}$ por $12 \mathrm{~h}$. Em seguida foram submetidos aos seguintes tratamentos: a) sanificação antes do descascamento; b) antes e após o descascamento; c) após o descascamento; d) sem sanificação (controle). O princípio ativo do sanificante utilizado foi Dicloro S. Triazinatriona Sódica. A sanificação antes do descascamento constou de imersão dos frutos em água, com $200 \mathrm{mg} . \mathrm{L}^{1}$ de

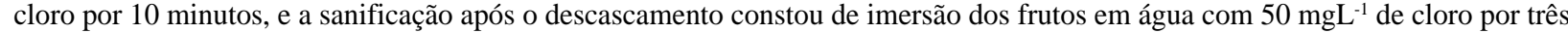
minutos, seguido de enxagüe em água potável. O descascamento foi realizado através de tratamento hidrotérmico (imersão das laranjas em água a $50^{\circ} \mathrm{C}$ por aproximadamente oito minutos). Posteriormente as laranjas foram descascadas manualmente e armazenadas a $6^{\circ} \mathrm{C}$ por seis dias. Os níveis de contaminação tanto por fungos como por bactérias foram baixos, atingindo no máximo $4 \times 10^{2} \mathrm{UFC} \cdot \mathrm{g}^{-1}$. Não foram detectados coliformes nem Salmonella em nenhuma amostra dos tratamentos. Embora todas as contagens microbianas tenham sido baixas em todos os tratamentos, naqueles nos quais se utilizou sanificação foram encontradas as menores contaminações, mostrando a eficácia da sanificação. Com base nestes resultados recomenda-se a sanificação antes do descascamento, após a operação de lavagem dos frutos para garantir a qualidade microbiológica.
\end{abstract}

Termos para indexação: Citrus sinensis, cloro, microbiologia, qualidade.

\section{ABSTRACT}

Sanitization is one of the most important procedures in minimal processing. This work aimed to determine the stage of the process in which sanitizing is more effective in orange. Fruits were selected according to size and skin color and stored at $6^{\circ} \mathrm{C}$ for $12 \mathrm{~h}$. Then, the following sanitization treatments were used: a) before peeling; b) before and after peeling; c) after peeling; d) no sanitization (control). The sanitizer active ingredient was Dichloro-S-Ttriazinetrione. For sanitization before peeling, fruits were immersed in water plus $200 \mathrm{mg} . \mathrm{L}^{1}$ chlorine for 10 minutes, while for sanitization after peeling, fruits were immersed in water plus $50 \mathrm{mg} . \mathrm{L}^{1}$ chlorine for 3 minutes, followed by rinsing in drinking water. Peeling was done by hydrothermic treatment (immersion of fruits in water at $50^{\circ} \mathrm{C}$ for 8 minutes approximately). After that, fruits were manually peeled and stored at $6^{\circ} \mathrm{C}$ for 6 days. Contamination levels by fungi and bacteria were low, reaching a maximum of $4 \times 10^{2} \mathrm{CFU} . \mathrm{g}^{-1}$. Coliforms or Salmonella were not found in any samples in treatments. Although microbial counts were low in all treatments, those using sanitization showed the lowest contamination levels, showing the sanitization efficacy. Based on the results, sanitization before peeling, after washing of fruits, is recommend in order to assure the microbiological quality of fruits.

Index terms: Citrus sinensis, cloro, microbiology, quality.

(Recebido em 23 de janeiro de 2007 e aprovado em 30 de julho de 2008)

Os produtos minimamente processados devem apresentar qualidade sensorial, nutricional e microbiológica. A vida útil desses produtos, em geral, é limitada pelo crescimento microbiano, o qual causa alterações nas características sensoriais e nutritivas dos produtos.
Os microrganismos patogênicos e deteriorantes podem contaminar os vegetais através de diversas maneiras tanto na pré como na pós-colheita. As fontes de contaminação na pré-colheita incluem o solo, a água de irrigação, água utilizada para aplicar fungicidas e inseticidas, poeira, insetos, compostagem inadequada de adubos,

\footnotetext{
1Engenheira Agrônoma, Doutora - Agência Paulista de Tecnologia dos Agronegócios, Pólo Centro Oeste, Unidade de Pesquisa de Bauru/APTA/PRDTA/ UPD - Av. Rodrigues Alves, 40-40 - Distrito Industrial -17034-285 - Bauru, SP - mcarruda@apta.sp.gov.br ${ }^{2}$ Egenheiro Agrônomo, Doutor - Produção Vegetal/LPV - Universidade de São Paulo, Escola Superior de Agricultura Luiz de Queiroz - Av. Pádua Dias, 11 - Bairro Agronomia Cx. P. 13418-900 - Piracicaba, SP - jacomino@esalq.usp.br

${ }^{3}$ Engeheira Agrônoma, Doutora em Agronomia - Gerência de Biotecnologia e Tratamentos Ambientais/CENPES/PDEDS/BTA - Petróleo Brasileiro S.A., PETROBRAS - Av. Horácio Macedo, 950 - 21941-598 - Rio de Janeiro, RJ - raquelmoreira@petrobras.com.br

${ }^{4}$ Graduação em Ciências Biológicas, Mestrado em Microbiologia Agrícola, Doutorado em Ciência de Alimentos - Agroindústria, Alimentos e Nutrição/LAN Escola Superior de Agricultura Luiz De Queiroz/ESALQ - Av. Pádua Dias,11 - Cx. P. 09 - Bairro Agronomia - 13418-900 - Piracicaba, SP crgallo@esalq.usp.br
} 
animais domésticos e selvagens, e a manipulação humana. Na pós-colheita, os principais focos são: manipulação humana, equipamentos de colheita, embalagens de transporte, animais, insetos, poeira, água de lavagem, gelo, transporte e equipamentos durante o processamento (BEUCHAT, 2002; BRACKETT, 1999).

No processamento mínimo, os procedimentos para eliminação de microrganismos ou controle do crescimento microbiano são poucos e incluem, principalmente, a lavagem, o uso de sanificantes, embalagens em atmosfera modificada, refrigeração (VANETTI, 2004) e alguns tratamentos adicionais, como por exemplo irradiação, películas comestíveis, entre outros.

A operação de sanificação no processamento mínimo apresenta importante papel na minimização da deterioração e na manutenção da qualidade do produto, e o cloro, nas suas várias formas, é o sanificante mais utilizado em alimentos (BRACKETT, 1992; DYCHDALA, 1991).

O cloro é barato, de fácil aplicação e monitorização e possui um amplo espectro de ação microbicida. Sua atividade antimicrobiana depende da quantidade de cloro livre disponível, particularmente em forma de ácido hipocloroso $(\mathrm{HOCl})$, do $\mathrm{pH}$ da solução, que deve estar entre 6,5 e 7,5, da temperatura da solução sanificante, sendo que, quanto menor, maior será a ação do cloro e da presença de matéria orgânica (DYCHDALA, 1991).

A sanificação tem se mostrado eficiente no controle da proliferação de microrganismos em citros, maçãs, alfaces, tomates e batatas minimamente processadas (PARK et al., 1991).

A RDC n ${ }^{\circ} 12$ da Agência Nacional de Vigilância Sanitária - ANVISA (2001) de 2 de janeiro de 2001 estabelece ausência de Salmonella em $25 \mathrm{~g}$ de produto e máximo de 5 x $10^{2} \mathrm{NMP}$ de coliformes a $45^{\circ} \mathrm{C}$ para frutas frescas, "in natura", preparadas, sanificadas, refrigeradas ou congeladas, para consumo direto.

Neste trabalho, a laranja foi sanificada em diferentes etapas do fluxograma de processo, de forma a definir em qual etapa é mais eficaz a sua utilização, visando obter um produto com qualidade microbiológica, que não cause problemas de saúde pública.

Laranjas 'Pêra', provenientes de pomares situados em Engenheiro Coelho, foram selecionadas, lavadas com detergente neutro e resfriadas a $6^{\circ} \mathrm{C}$ por 12 horas. Após o resfriamento as laranjas foram submetidas aos tratamentos: a) sanificação antes do descascamento; b) antes e após o descascamento; c) após o descascamento; d) sem sanificação (controle). O sanificante utilizado foi o Dicloro S. Triazinatriona Sódica.

A sanificação antes do descascamento constou de imersão dos frutos em água mineral com $200 \mathrm{mg} . \mathrm{L}^{1}$ de cloro por 10 minutos, enquanto a sanificação após o descascamento constou de imersão dos frutos em água mineral, com $50 \mathrm{mg} . \mathrm{L}^{-1}$ de cloro por três minutos, seguido de enxague em água mineral.

$\mathrm{O}$ descascamento foi realizado através de tratamento hidrotérmico (imersão das laranjas em água a $50^{\circ} \mathrm{C}$, por aproximadamente oito minutos). Em seguida, as laranjas foram descascadas manualmente e armazenadas a $6^{\circ} \mathrm{C}$.

$\mathrm{O}$ delineamento foi inteiramente casualizado, utilizando-se para cada dia de análise dois frutos por tratamento.

A microbiota contaminante foi avaliada pelo número mais provável de coliformes totais e a $45^{\circ} \mathrm{C}$, presença/ ausência de Salmonella, contagem total de bactérias psicrotróficas e bolores e leveduras. Coliformes e Salmonella foram determinados no dia do processamento e no terceiro e sexto dia de armazenamento. Bolores e leveduras e bactérias psicrotróficas foram determinados no sexto dia de armazenamento.

Para contagem de bactérias psicrotróficas, utilizouse o meio Ágar Padrão para Contagem (PCA). As análises foram efetuadas em porções de $50 \mathrm{~g}$ de fruto ( $25 \mathrm{~g}$ por fruto), pesadas assepticamente e colocadas em liquidificador esterilizado, com $450 \mathrm{~mL}$ de água peptonada $(0,1 \%)$ estéril, constituindo a diluição $10^{-1}$, após homogeneização. A partir da diluição $10^{-1}$, obteve-se a diluição $10^{-2}$, pipetando-se 10 $\mathrm{mL}$ da solução $10^{-1} \mathrm{em} 90 \mathrm{~mL}$ de água peptonada esterilizada $(0,1 \%)$ e a partir dessa, obteve-se a diluição $10^{-3}$.

A partir da diluição $10^{-1}$ até a $10^{-3}$ foram plaqueados em profundidade, $1 \mathrm{~mL}$ de cada diluição em duplicata, utilizando-se $20 \mathrm{~mL}$ de meio de cultivo PCA. Após o plaqueamento as placas permaneceram em repouso até completa solidificação do meio, sendo então invertidas e incubadas a $7^{\circ} \mathrm{C}$ por 10 dias.

Decorrido o tempo de incubação, fez-se a contagem das colônias, com auxílio do contador de colônias tipo Quebec. Multiplicou-se a média aritmética da duplicata pelo respectivo fator de diluição. Os resultados foram expressos em unidades formadoras de colônias (UFC. $\mathrm{g}^{-1}$ de produto).

Coliformes foram determinados pelo método do Número Mais Provável (NMP), através da técnica dos Tubos Múltiplos. Para o teste presuntivo foram utilizadas séries de cinco tubos de ensaio para cada diluição $\left(10^{-1}\right.$, $10^{-2}$ e $10^{-3}$ ), os quais continham um tubo de Durham e caldo lauril (LST) em concentração simples. Adicionou-se $1 \mathrm{~mL}$ de cada diluição nas referidas séries de 5 tubos.

Todos os tubos foram incubados em estufa termostatizada a $35-37^{\circ} \mathrm{C}$, por $24-48$ horas de incubação. A possível presença de tubos positivos é observada pelo esvaziamento dos tubos de Durham, devido à produção 
de gás pelas bactérias do grupo coliforme ao fermentarem a lactose.

Caso houvesse tubos positivos no teste presuntivo, ou seja, esvaziamento do tubo de Durhan, alíquotas destes tubos deveriam ser inoculadas em tubos com caldo verde brilhante Lactose Bile (CVBLB) e em tubos com caldo Escherichia coli (EC). Os tubos CVBLB deveriam ser incubados a $35-37^{\circ} \mathrm{C} / 24-48 \mathrm{~h}$ para o teste confirmativo de coliformes totais e os tubos EC em banhomaria a $45^{\circ} \mathrm{C} / 24 \mathrm{~h}$ para o teste confirmativo de coliformes a $45^{\circ} \mathrm{C}$.

Para detecção de Salmonella, utilizou-se o Kit '1-2 test', fabricado pela BioControl/USA. Foi feito um préenriquecimento de cada amostra analisada, triturando-se $25 \mathrm{~g}$ de fruto em $225 \mathrm{~mL}$ de água peptonada tamponada esterilizada, em liquidificador esterilizado. Após a homogeneização, foi feita assepticamente a transferência para os frascos erlenmeyers originais (que continham os $225 \mathrm{~mL}$ de água peptonada tamponada). Tais frascos foram incubados em estufa termostatizada, a $35^{\circ} \mathrm{C}$ por 24 horas. Decorrido o período de incubação, fez-se o preparo dos kits, inoculando $0,1 \mathrm{~mL}$ da amostra. Incubaram-se os kits a $35^{\circ} \mathrm{C}$ por 24 horas. Após a incubação foi feita a leitura dos resultados. A possível presença de Salmonella é caracterizada pela formação de uma imunobanda na metade superior do gel. Trata-se de uma banda branca que apresenta forma de $\mathrm{U}$ formada pela aglutinação das células da bactéria.

Para contagem de bolores e leveduras, utilizou-se o meio Batata Dextrose Ágar (BDA) acidificado com ácido tartárico $(\mathrm{pH} \cong 4,0)$.

As análises foram efetuadas em porções de $50 \mathrm{~g}$ de fruto ( $25 \mathrm{~g}$ por fruto), pesadas assepticamente e trituradas em liquidificador esterilizado, com $450 \mathrm{~mL}$ de água peptonada $(0,1 \%)$ estéril, constituindo a diluição $10^{-1}$. A partir da diluição $10^{-1}$, obteve-se a diluição $10^{-2}$, pipetando-se $10 \mathrm{~mL}$ da solução $10^{-1} \mathrm{em} 90 \mathrm{~mL}$ de água peptonada esterilizada $(0,1 \%)$ e a partir dessa, obteve-se a diluição $10^{-3}$.

A partir da diluição $10^{-1}$ até a $10^{-3}$ foram plaqueados em profundidade, $1 \mathrm{~mL}$ de cada diluição em duplicata, utilizando-se $20 \mathrm{~mL}$ de meio de cultivo BDA. Após o plaqueamento as placas de Petri permaneceram em repouso até completa solidificação do meio, sendo então invertidas e incubadas a $30^{\circ} \mathrm{C}$ por três a cinco dias.

Decorrido o tempo de incubação fez-se a contagem das colônias, com auxílio do contador de colônias tipo Quebec. Multiplicou-se a média aritmética da duplicata pelo respectivo fator de diluição. Os resultados foram expressos em UFC. $\mathrm{g}^{-1}$ de produto.

Os níveis de contaminação tanto por bolores e leveduras como por bactérias psicrotróficas foram baixos, atingindo no máximo 4,0 x $10^{2} \mathrm{UFC} \mathrm{g}^{-1}$ (Tabela 1 ).

Observaram-se os menores níveis de contaminação por bactérias psicrotróficas nos tratamentos com sanificação. Em relação às contagens de bolores e leveduras também ficou claro que, embora os níveis de contaminação tenham sido baixos em todos os tratamentos, naqueles nos quais se utilizou sanificação foram encontradas as menores contagens após o período de armazenamento. Os resultados obtidos evidenciam que os microrganismos, nas laranjas minimamente processadas, foram provenientes da superfície da casca do fruto.

Esses resultados estão de acordo com Ngarmsak et al. (2006) os quais observaram que fatias de mangas preparadas a partir de frutos sem sanificação apresentaram maior nível de microrganismos em relação às fatias provenientes de frutos sanificados em água $\left(11,7^{\circ} \mathrm{C}\right)$, com $100 \mathrm{mg} . \mathrm{L}^{-1}$ de cloro ou provenientes de frutos imersos em água a $50^{\circ} \mathrm{C}$ por cinco minutos com ou sem $100 \mathrm{mg} . \mathrm{L}^{-1}$ de cloro.

Tanto o cloro quanto a água quente interferem no crescimento microbiano. Os compostos clorados, em solução aquosa, liberam o ácido hipocloroso $(\mathrm{HOCl})$ e o íon hipoclorito ( $\left.\mathrm{CLO}^{-}\right)$, sendo o ácido hipocloroso o agente bactericida, pois não tem carga elétrica e é capaz de atravessar a membrana celular dos microrganismos e paralisar a produção de energia proveniente da glicólise, oxidar proteínas celulares, interferir no transporte de nutrientes e promover a perda de componentes celulares, levando o microrganismo à morte (ANDRADE et al., 1985; DYCHDALA, 1991).

Tabela 1 - Unidades formadoras de colônias (UFC) de bactérias psicrotróficas, bolores e leveduras por grama (g) de laranja 'Pera' minimamente processada após seis dias de armazenamento a $6^{\circ} \mathrm{C}$.

\begin{tabular}{lcc}
\hline \multicolumn{1}{c}{ Tratamento } & Bolores e Leveduras & Bactérias Psicrotróficas \\
\hline Controle & $4,0 \times 10$ & $4,0 \times 10^{2}$ \\
Sanificação após o descascamento & $1,0 \times 10$ & $<10$ \\
Sanificação antes do descascamento & $1,5 \times 10$ & $<10$ \\
Sanificação antes e após o descascamento & $2,0 \times 10$ & $<10$ \\
\hline
\end{tabular}

Ciênc. agrotec., Lavras, v. 33, Edição Especial, p. 1866-1870, 2009 
Quanto à utilização de água quente, essa pode causar injúrias aos microrganismos e inabilitar a recuperação do estresse adquirido durante o tratamento (NGARMSAK et al., 2006). Sertthikul et al. (2003), citados por Ngarmsak et al. (2006) observaram que a imersão a $60^{\circ} \mathrm{C}$ por 20 minutos ou $62^{\circ} \mathrm{C}$ por quatro minutos eliminou $86 \%$ da Salmonella entérica spp inoculada em manga. Diante desse fato, pode-se inferir que, no presente trabalho, a imersão dos frutos sanificados em água a $50^{\circ} \mathrm{C}$ por oito minutos contribuiu para potencializar a redução da carga inicial de microrganismos.

Não foram detectados coliformes nem Salmonella, em nenhuma amostra dos tratamentos, estando portanto, as amostras em acordo com a RDC n ${ }^{\circ} 12$ que estabelece ausência de Salmonella em $25 \mathrm{~g}$ de produto e máximo de 5 x $10^{2} \mathrm{NMP}$ de coliformes a $45^{\circ} \mathrm{C}$ para frutas frescas, "in natura", preparadas, sanificadas, refrigeradas ou congeladas, para consumo direto.

De acordo com a "International Commission on Microbiological Specifications for Foods - ICMSF (1978), a presença de coliformes em alimentos indica manipulação inadequada durante o processamento, uso de equipamentos em más condições sanitárias ou ainda utilização de matéria-prima contaminada. Assim, como os coliformes, a Salmonella pertence à família das Enterobacteriaciae e os principais focos de infecção são as fezes humanas e de animais. Portanto, a ausência desses microrganismos nas laranjas minimamente processadas é reflexo da ótima qualidade da matéria-prima utilizada e das boas práticas de fabricação adotadas durante todo o processamento.

É importante salientar que, em processamento mínimo, independentemente do produto a ser processado, a matéria-prima deve ser de excelente qualidade. Além disso, devem-se adotar medidas preventivas para minimizar a contaminação dos produtos em toda cadeia produtiva. A implantação de um sistema efetivo de controle, por meio de programa de Análise de Perigos e Pontos Críticos de Controle (APPCC) é fundamental para o conhecimento e prevenção da contaminação e do crescimento microbiano em produtos minimamente processados (VANETTI, 2000).

Embora todas as contagens microbianas encontradas nos tratamentos tenham sido baixas (máximo de $4,0 \times 10^{2} \mathrm{UFC} / \mathrm{g}$ ) e, portanto, todas as amostras se encontravam de acordo com os padrões microbiológicos pertinentes e assim satisfatórias, sob o aspecto microbiológico para o consumo humano, ficou evidente o benefício da sanificação e é recomendável que a mesma seja efetuada após a operação de lavagem dos frutos, antes do descascamento, para se evitar a contaminação do hesperídeo, caso o fruto venha do campo com maior contaminação microbiana.

\section{REFERÊNCIAS BIBLIOGRÁFICAS}

AGENCIA NACIONAL DE VIGILÂNCIA SANITÁRIA.

Resolução RDC n. 12, de 2 de janeiro de 2001.

Disponível em: <http://e-legis.anvisa.gov.br/leisref

public/showAct.php?id=144\&word=limite\%2d

microbiologico'. Acesso em: 16 out. 2006.

ANDRADE, N. J.; MOSQUIM, M. C. A. V.; CHAVES, J. B. P.; TEIXEIRA, M. A. Efeito da concentração e do pH na ação sanitizante de soluções diluídas de hipoclorito de sódio comercial. Revista do Instituto de Laticínios

Candido Toste, Rio de Janeiro, v. 40, p. 73-83, 1985.

BEUCHAT, L. R. Ecological factors influencing survival and growth of human pathogens on raw fruit and vegetables. Microbes and Infection, Berlin, v. 4, n. 4, p. 413-423, 2002.

BRACKETT, R. E. Shelf stability and safety of fresh cut produce as a influenced by sanitation. Journal of Food Protection, Des Moines, v. 55, p. 808-814, 1992.

BRACKETT, R. E. Incidence, contributing factors, and control of bacterial pathogens in produce. Postharvest Biology and Technology, Amsterdam, v. 15, n. 3, p. 305311, 1999.

DYCHDALA, G. R. Chlorine and chlorine compounds. In: BLOCK, S. S.; BARKLEY, W. E. Desinfection

sterilization and preservation. 4. ed. Philadelphia: Lea \& Febiger, 1991. p. 131-151.

\section{INTERNATIONAL COMMISSION ON}

MICROBIOLOGICAL SPECIFICATIONS FOR FOODS.

Microorganisms in foods. 2. ed. Toronto: University of Toronto, 1978. v. 1, 434 p.

NGARMSAK, M.; DELAQUIS, P.; TOIVONEN, P.

Microbiology of fresh-cut mangoes prepared from fruit sanitized in hot chlorinated water. Food Science

Technology International, Madrid, v. 12, n. 6, p. 95-103, 2006.

PARK, D. L.; RUA JUNIOR, S. M.; ACKER, R. F. Direct application of a new hypochlorite sanitizer for reducing bacterial contamination on foods. Journal of Food

Protection, Des Moines, v. 54, n. 12, p. 960-965, 1991. 
VANETTI, M. C. D. Controle microbiológico e higiene no processamento mínimo. In: ENCONTRO NACIONAL SOBRE PROCESSAMENTO MÍNIMO DE FRUTAS E HORTALIÇAS, 2., 2000, Viçosa. Palestras...Viçosa: CEE, 2000. p. 44-52.
VANETTI, M. C. D. Segurança microbiológica em produtos minimamente processados. In: ENCONTRO NACIONAL SOBRE PROCESSAMENTO MÍNIMO DE FRUTAS E HORTALIÇAS, 3., 2004, Viçosa. Palestras, Resumos e Oficinas...Viçosa: CEE, 2004. p. 30-32. 